\title{
Precursor mRNA
}

National Cancer Institute

\section{Source}

National Cancer Institute. Precursor mRNA. NCI Thesaurus. Code C111298.

A primary RNA transcript synthesized from a DNA template in eukaryotic nuclei which is post-transcriptionally modified and spliced to produce a mature mRNA. 